\title{
EFFECTS OF OXIDATION AND HOT CORROSION IN A NICKEL DISC ALLOY
}

\author{
A. Encinas-Oropesa ${ }^{1}$, G.L. Drew ${ }^{2}$, M.C. Hardy ${ }^{2}$, A.J. Leggett ${ }^{2}$, J.R. Nicholls ${ }^{1}$ and N.J. Simms ${ }^{1}$ \\ ${ }^{1}$ Cranfield University, Cranfield, Bedfordshire, MK43 0AL, UK \\ ${ }^{2}$ Rolls-Royce plc., PO Box 31, Derby, DE24 8BJ, UK.
}

Keywords: Oxidation, Hot corrosion, Alloy RR1000

\begin{abstract}
This paper describes work to study oxidation and hot corrosion damage in nickel disc alloy RR1000. Oxidation damage has been characterised via mass change data from thermogravimetric analyses at temperatures from 700 to $800{ }^{\circ} \mathrm{C}$ and cyclic oxidation testing at 700 and $750^{\circ} \mathrm{C}$. Thin oxide scales rich in $\mathrm{Cr}$ and $\mathrm{Ti}$ have been found to grow in a parabolic dependence with time. Oxidation rate constants have been correlated with temperature using an Arrhenius equation. Through the use of simplifying assumptions, mass change data have been converted to oxide thickness values. These values have been compared with observed values of oxide scale and the depth of near-surface damage, which have been measured using focused ion beam (FIB) microscopy.
\end{abstract}

Hot corrosion of RR1000 has been studied in the laboratory by 'deposit' recoat experiments at $700^{\circ} \mathrm{C}$. In these tests, samples were coated with deposits of $\mathrm{Na}_{2} \mathrm{SO}_{4} / \mathrm{NaCl}$ salt in a gas stream of air-300 vpm $\mathrm{SO}_{2}$. Corrosion damage has been quantified by dimensional metrology of samples before and after exposure. This enabled metal losses, i.e. the depth of corrosion pits, to be determined. Distributions of metal loss data were then generated to produce median damage values and exceedance cumulative probabilities. Finally, the effect of contaminants on the hot corrosion resistance of RR1000 has also been evaluated.

\section{Introduction}

To meet the demand for reduced acquisition and life cycle costs in civil aviation, modern gas turbine engines are expected to achieve increasingly higher levels of fuel economy, reduced NOx emissions and noise, and with reduced module weight. These challenges inevitably necessitate higher overall pressure ratios, and higher compressor discharge and turbine entry temperatures. As such, disc rotors in the High Pressure (HP) compressor and turbine must accommodate higher temperatures and stresses. This places significant demands on the high strength nickel alloys that are used for these critical components, particularly as loss of integrity can threaten the safety of the aircraft and passengers.

Exposure of HP turbine disc rotors in the engine environment to prolonged periods at high temperature produces surface oxidation and hot corrosion. It is well established that oxidation can reduce fatigue life in nickel disc alloys at temperatures in excess of $500^{\circ} \mathrm{C}$. This can result from cracking of surface oxide scale $[1,2]$ and accelerated rates of crack growth due to an increased propensity for intergranular cracking $[1,3]$. Several mechanisms have been proposed to account for this crack growth behaviour. The most likely explanation involves the modification of grain boundary microstructure ahead of the crack tip by grain boundary diffusion of oxygen. This reduces the ability for grain boundary regions to accommodate stress concentrations that result from slip and grain boundary sliding, which is prevalent at these high temperatures [4].

Hot corrosion is considered more severe in aircraft engines that are used for air travel near coastal areas, and over deserts and volcanic regions. During these flights, high chloride bearing salts and fine sulphate bearing sands are ingested in the engines. These species can pass through the engine to the hot gas path of the HP turbine, and can result in deposits being formed on areas of the blades, vanes and the disc rim by particle and/or vapour deposition. The presence of sulphur dioxide, a by-product of combustion, assists the formation of sodium sulphate $\left(\mathrm{Na}_{2} \mathrm{SO}_{4}\right)$ rich deposits. At temperatures in excess of $650^{\circ} \mathrm{C}$, these $\mathrm{Na}_{2} \mathrm{SO}_{4}$ deposits react with the $\mathrm{Ni}$ alloy components to form low melting point eutectics that attack the component surface. This mode of hot corrosion is known as type II sulphidation.

In this paper, the results of laboratory experiments to characterise oxidation and hot corrosion of Ni disc alloy, RR1000 [5], are reported.

\section{Nickel Disc Alloy RR1000}

RR1000 is a $\gamma^{\prime}$ precipitation hardened Ni base alloy that has been developed by Rolls-Royce for disc rotor applications up to $725^{\circ} \mathrm{C}$ [5]. It has a nominal composition of $18.5 \mathrm{Co}-15 \mathrm{Cr}-5 \mathrm{Mo}-3.6 \mathrm{Ti}-$ 3Al-2Ta-0.5Hf-0.03C-0.02B-0.06Zr wt.\%, balance Ni.

Material for the work reported in this paper was taken from fully heat-treated forgings, which were produced from HIP and extruded powder billet. The average grain size was between ASTM 13-11 with isolated grains as large as (ALA) ASTM 8.

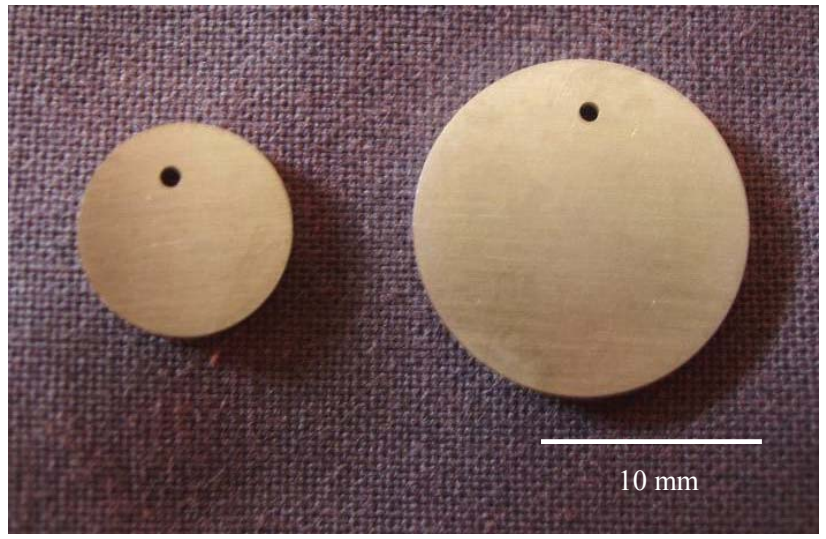

Figure 1 Discs used for thermogravimetric analysis (left) and cyclic oxidation testing (right). 


\section{A Study of Oxidation Behaviour}

\section{Experimental Work to Measure Oxidation Damage}

Oxidation has been studied at temperatures between 700 and $800^{\circ} \mathrm{C}$ by thermogravimetric analysis (TGA) and cyclic oxidation testing at 700 and $750^{\circ} \mathrm{C}$, via a resistance furnace and microbalance.

For these isothermal and cyclic oxidation tests, discs of RR1000 were prepared by grinding to a surface finish of $0.25 \mu \mathrm{m}$ and a surface integrity that is comparable to fatigue test pieces that are used to generate materials property data. The dimensions of these discs were different for these two types of testing due to limitations of sample weights in the high resolution TGA system. Thus, disc dimensions (with tolerances of $+/-0.005 \mathrm{~mm}$ ) were:

- $\quad 16 \mathrm{~mm}$ in diameter, $2 \mathrm{~mm}$ thickness, and hole diameter of 1 $\mathrm{mm}$ for cyclic testing,

- $10 \mathrm{~mm}$ in diameter, $1.5 \mathrm{~mm}$ thickness, and hole diameter 1 $\mathrm{mm}$ for TGA.

All disc samples (Figure 1) were cleaned and degreased before their exposure in the oxidation tests. The cleaning practice consisted of 15 minute periods in a degreaser (Volasil) and a further 15 minutes in isopropyl alcohol.

The series of isothermal oxidation tests were carried out in a Setaram 'Setsys Evaluation' thermogravimetric analysis (TGA) system. This system allows a single sample of $<1 \mathrm{~g}$ to be exposed at a temperature of up to $2400^{\circ} \mathrm{C}$ in a controlled atmosphere environment. During the exposures, the weight of the sample (to a resolution of $10 \mu \mathrm{g}$ ) and the temperature of the sample exposure zone were monitored at regular intervals (50 seconds) and automatically recorded on the computerised control system.

Isothermal tests were undertaken at $700,725,750,775$, and $800^{\circ} \mathrm{C}$ in dry air (bottle supplied) for periods of 200 hours. For one test at $700^{\circ} \mathrm{C}$, there was a power supply disruption that caused the test to terminate after 140 hours; this test was repeated for the intended 200 hour exposure.

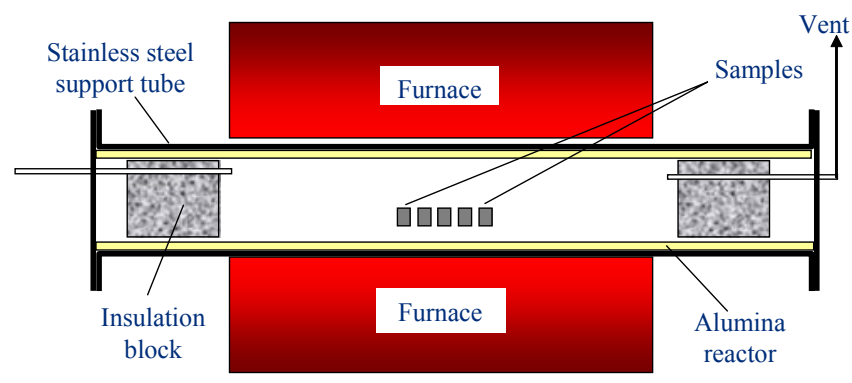

Figure 2. Schematic diagram of horizontal furnace for cyclic oxidation testing.

The cyclic oxidation tests were performed in a horizontal controlled atmosphere furnace (Figure 2). For these simple oxidation tests, no gas was passed through the furnace, so the atmosphere was laboratory air. All disc samples were measured before exposure using a micrometer, with a resolution of $1 \mu \mathrm{m}$.
The accuracy of the micrometer is regularly checked against slip gauges, giving values of $+/-2 \mu \mathrm{m}$.

All disc samples were weighed before their exposure, after each exposure cycle and after completion of their total exposure period. They were measured using a balance with a resolution of $0.01 \mathrm{mg}$. The balance was calibrated daily using its internal calibration function; test weights are used to check the balance on a weekly basis.

Tests were carried out at 700 and $750^{\circ} \mathrm{C}$ for 1000 hours, with samples being cycled slowly to room temperature every 100 hours. In both these tests, a series of 5 samples were exposed, with target exposure times of $100,200,500$ and two at 1000 hours.

The isothermal oxidation sample exposed at $700^{\circ} \mathrm{C}$ for 140 hours had areas of interference colour and areas of grey oxides. All other isothermal oxidation samples, exposed for 200 hours at $700^{\circ} \mathrm{C}$ or higher temperatures, showed just grey oxide layers.

From the cyclic oxidation tests, only the sample exposed at $700^{\circ} \mathrm{C}$ for 100 hours showed interference colours on its surface. All of the other exposures produced a grey coloured oxide.

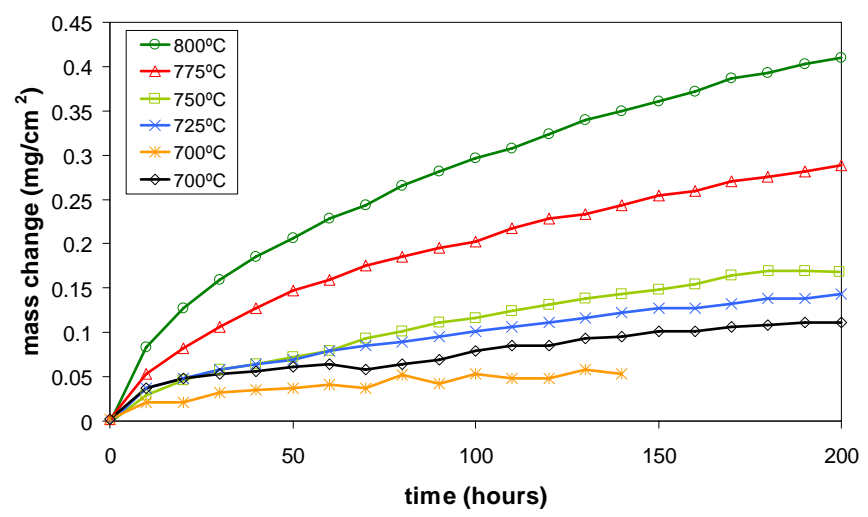

Figure 3. Mass change data for RR1000 from thermogravimetric analyses (up to 200 hours, from $700-800^{\circ} \mathrm{C}$ ).

Mass change data, shown in Figure 3, from the isothermal oxidation exposures indicate that;

- the alloy exhibits low rates of oxidation damage,

- rates of mass gain increase with increasing temperature,

- oxidation behaviour is approximately parabolic,

- repeat isothermal exposures at $700^{\circ} \mathrm{C}$ show the level of scatter $\left(+/-0.01 \mathrm{mg} / \mathrm{cm}^{2}\right)$ expected during oxidation testing.

It should be noted that net mass change of the sample is measured and tends to refer to mass gain, but can accommodate the effects of spallation. Also, the variation shown in mass change data from the two tests at $700^{\circ} \mathrm{C}$ is considered to apply to all of the measured data. This is indicated later in Figure 5, in which a curve to correlate parabolic rate constant data with the reciprocal of temperature falls very close to data for other temperatures and mid-way between the data points for $700^{\circ} \mathrm{C}$.

After 200 hours, from which mass change data from isothermal and cyclic oxidation could be compared, mass change values from 
cyclic exposures were lower than those in the isothermal tests at both 700 and $750^{\circ} \mathrm{C}$.

\section{Characterisation of Oxidation Kinetics}

High temperature oxidation is often reported in the literature to be a form of diffusion dependant oxide growth, which has a parabolic dependence on time. This was confirmed for the mass change data gathered in both the isothermal and cyclic oxidation tests by plotting (mass change) ${ }^{2}$ as a function of time. This is illustrated in Figure 4 using data from isothermal oxidation tests. These mass data are close to fitting the classical view of high temperature oxidation. It should be noted that the oxide growth theory on which parabolic oxide growth is based requires parallel sided, uniform oxide scales that are not always observed in practical situations.

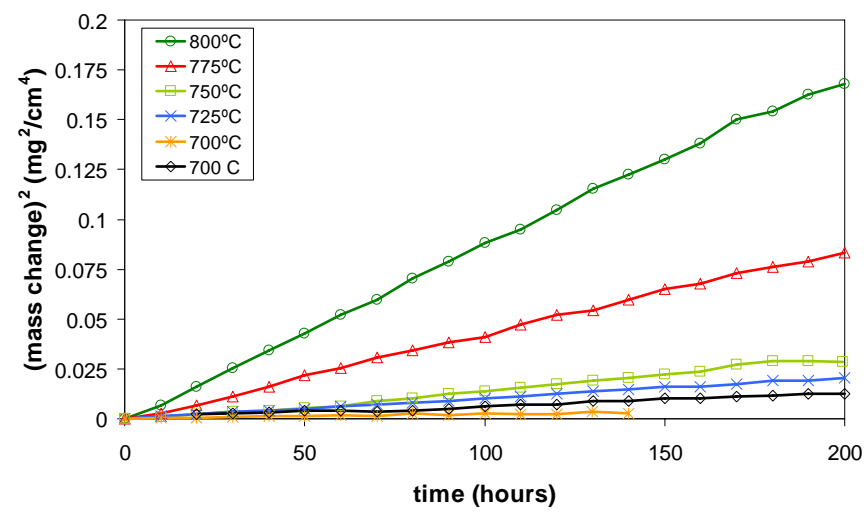

Figure 4 Mass change data for RR1000 from isothermal testing plotted as (mass change) ${ }^{2}$ against time.

In view of the generally parabolic oxidation behaviour, a simple parabolic oxidation curve has been fitted to the mass change data from each of these exposures, such that,

$$
(\text { mass } \cdot \text { change })^{2}=K_{p} \cdot t
$$

where mass change is measured in $\mathrm{mg} / \mathrm{cm}^{2}$ and time $(\mathrm{t})$ in hours, so that the parabolic rate constant $\left(\mathrm{K}_{\mathrm{p}}\right)$ is calculated in $\mathrm{mg}^{2} / \mathrm{cm}^{4} /$ hour.

Further analysis of these data, assuming the parabolic oxidation rate, is possible using an Arrhenius plot (Figure 5). The basis for this type of plot is the assumption that the temperature dependence of the parabolic rate constant can be represented as:

$$
\mathrm{K}_{\mathrm{p}}=\mathrm{K}_{\mathrm{o}} \cdot \exp \left(\frac{-\mathrm{Q}}{\mathrm{RT}}\right)
$$

where $\mathrm{Q}$ is an activation energy for oxide growth, $\mathrm{R}$ is the gas constant, $\mathrm{T}$ is the exposure temperature (in ${ }^{\circ} \mathrm{K}$ ) and $\mathrm{K}_{\mathrm{o}}$ is a constant.

Thus, a plot of the form 'In $K_{p}$ ' versus ' $1 / T$ ' should produce a straight line with a gradient of ' $-\mathrm{Q} / \mathrm{R}$ '. Figure 5 shows a good straight line fit for the isothermal exposure data. The gradient of this line gives an activation energy of $\sim 270 \mathrm{~kJ} / \mathrm{mol}$, which is higher than literature values $(256 \mathrm{~kJ} / \mathrm{mol}$ or $61.1 \mathrm{kcal} / \mathrm{mol})$ for $\mathrm{Cr}_{2} \mathrm{O}_{3}$ growth [6], although the tests in the current study have been carried out at much lower temperatures. Chen et al [7] reported activation energies of 250,270 and $300 \mathrm{~kJ} / \mathrm{mol}$ for nickel disc alloys Udimet 720, Astroloy and Waspaloy, which were determined from isothermal exposures and cyclic oxidation testing at $750-1000^{\circ} \mathrm{C}$. The compositions of these alloys (Table I) are very similar to RR1000 in terms of $\mathrm{Cr}$, Ti, Co and Ni content and were found to show the same oxides (as discussed in the next section).

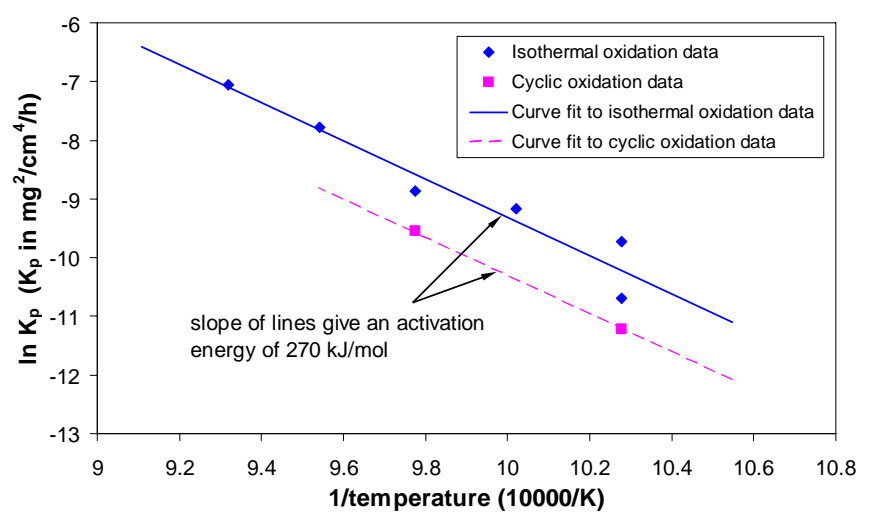

Figure 5. Graph showing the natural logarithm of the calculated parabolic rate constant for RR1000 versus the reciprocal of temperature in degrees Kelvin.

Table I. Composition of nickel disc alloys reported in Chen et al [7] and in the current study.

\begin{tabular}{|c|c|c|c|c|c|c|c|c|c|c|c|c|c|}
\hline Alloy & $\mathrm{Cr}$ & $\mathrm{Co}$ & $\mathrm{Mo}$ & $\mathrm{W}$ & $\mathrm{Nb}$ & $\mathrm{Ti}$ & $\mathrm{Al}$ & $\mathrm{Ta}$ & $\mathrm{Hf}$ & $\mathrm{Zr}$ & $\mathrm{C}$ & $\mathrm{B}$ & $\mathrm{Ni}$ \\
\hline Waspaloy & 19.5 & 13.5 & 4 & 0 & 0 & 3 & 1.4 & 0 & 0 & 0.05 & 0.06 & 0.007 & Rem. \\
\hline Astroloy & 15 & 17 & 5 & 0 & 0 & 3.5 & 4 & 0 & 0 & 0 & 0.06 & 0.03 & Rem. \\
\hline 720 & 18 & 15 & 3 & 1.25 & 0 & 5 & 2.5 & 0 & 0 & 0.04 & 0.02 & 0.035 & Rem. \\
\hline RR1000 & 15 & 18.5 & 5 & 0 & 0 & 3.6 & 3 & 2 & 0.5 & 0.06 & 0.03 & 0.015 & Rem. \\
\hline
\end{tabular}

Whilst the limited data indicate that the activation energy for cyclic oxidation is similar to that for isothermal exposure (Figure 5 ), the rate constants from the two completed cyclic oxidation tests are lower than those from the isothermal oxidation tests. This could be a result of a combination of factors:

- oxidation behaviour is not parabolic at the start of the exposures for both isothermal and cyclic testing, such that a complex parabolic equation is required for better data fitting,

- oxide growth which is initially non-uniform becomes more uniform during the course of the exposures, i.e. the oxidation reaction deviates from true parabolic behaviour for shorter exposure times.

- the formation of nickel chromium spinels (see Composition of Oxides Scales) from early transient oxidation. Unlike chromia, it is considered that these oxides may spall during cyclic oxidation, which will produce less apparent net mass gain and cause the oxidation reaction to deviate from true parabolic oxidation, at least for the longer of the exposure times.

Spallation is considered to occur as a result of stresses, which arise from changes in volume and thermal stresses as a result of differences in coefficients of thermal expansion between the scale and the alloy substrate. The lower mass gains from cyclic exposures are not attributed to water vapour since the humidity levels in the laboratory were less than $2 \%$. Chromia can react with water vapour in air to form oxy-hydroxides such as $\mathrm{CrO}_{2}(\mathrm{OH})_{2}$, which are volatile and may evaporate. This has been 
shown in austenitic stainless steels and nickel alloys (HX and 625) from exposures at 704 and $760^{\circ} \mathrm{C}$ in air that contains deliberate additions of 7 and $10 \%$ water vapour [8].

A further analysis of the mass change data is a conversion to oxide thickness values. This analysis requires the simplifying assumptions of a uniform oxide scale in terms of thickness and density (and therefore composition). It is assumed that the:

- $\quad$ oxide formed is chromia $\left(\mathrm{Cr}_{2} \mathrm{O}_{3}\right)$,

- $\quad$ it is fully dense, i.e. contains no pores,

- molecular weight of $\mathrm{Cr}_{2} \mathrm{O}_{3}=151.99 \mathrm{~g}$,

- atomic weight of $\mathrm{O}$ is $16 \mathrm{~g}$,

- density of $\mathrm{Cr}_{2} \mathrm{O}_{3}=5.21 \mathrm{~g} / \mathrm{cm}^{2}$,

then:

$$
1 \mathrm{mg} / \mathrm{cm}^{2} \text { mass increase } \quad=(151.99 \times 10) /(3 \times 16 \times 5.21)
$$$$
=6.08 \mu \mathrm{m} \text { of } \mathrm{Cr}_{2} \mathrm{O}_{3} \text {. }
$$

Figure 6 shows the result of converting the isothermal mass change data to oxide layer thickness using this method. These data will be compared with observed thicknesses of oxide scale in a later section. The assumption that the scale is chromia is examined in the following text.

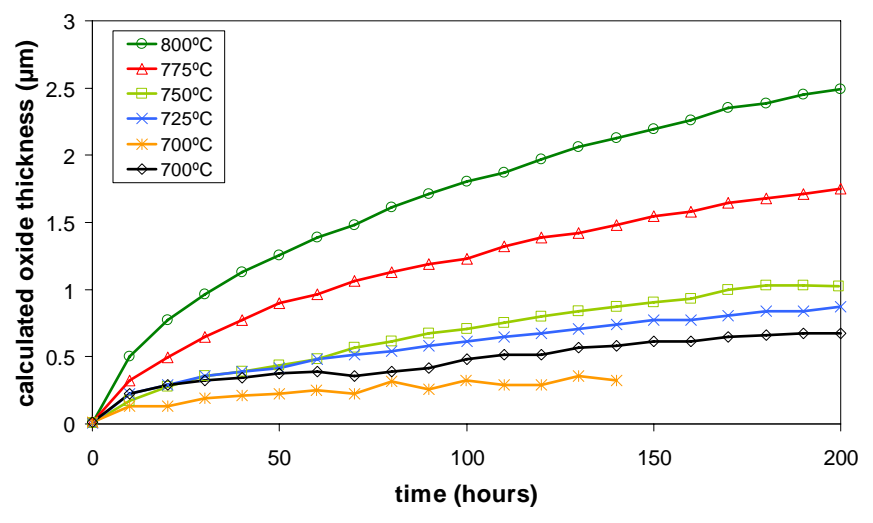

Figure 6. Thickness of $\mathrm{Cr}_{2} \mathrm{O}_{3}$ scale, calculated from mass change data for RR1000, which were measured from thermogravimetric analysis (up to 200 hours, from $700-800^{\circ} \mathrm{C}$ ).

\section{$\underline{\text { Composition of Oxide Scales }}$}

A conventional vertical $\mathrm{x}$-ray diffractometer (Siemens D5005) was used to undertake $\mathrm{x}$-ray diffraction (XRD) on disc samples exposed in both the isothermal and the cyclic oxidation tests. The only oxide that was detected by XRD was $\mathrm{Cr}_{2} \mathrm{O}_{3}$ and this was detected only on the sample that had been oxidised isothermally at $800^{\circ} \mathrm{C}$ for 200 hours. This sample had recorded the highest mass gain of all those exposed and so is predicted to have the thickest oxide layer $(\sim 2.5 \mu \mathrm{m}$ using the calculation method above, Figure 6). The other samples had oxide scales that were too thin to be analysed by XRD. The x-rays penetrated through the oxide scales into the base alloys, with the signals from the oxide scale being too low to detect using conventional XRD.

Energy dispersive x-ray analyses (EDX) of the surface scales were carried out in a Field Emission Gun Scanning Electron Microscope (FEG-SEM). Again it was anticipated that these analyses would have a large contribution from the base alloy, due to the thin oxide scales being examined. However, the changes in concentrations of the elements in the oxide scale and, or near surface region, with increasing sample exposure time and temperature, indicates the elements which are participating in the oxidation reactions. The results are summarised in Table II for samples exposed in the isothermal oxidation tests. These show progressive enrichment of $\mathrm{Cr}$ and $\mathrm{Ti}$ in the oxide scale with increasing time and/or temperature, coupled with lower $\mathrm{Ni}$ and $\mathrm{Co}$ levels. This is consistent with the formation of $\mathrm{Cr}_{2} \mathrm{O}_{3}$ and $\mathrm{TiO}_{2}$ oxides on the sample surfaces and the reduction of EDX signal coming from the substrate as oxide thickness increases.

Table II. Composition of thin oxide scales as a function of exposure temperature and time. Compositions were determined through energy dispersive x-ray analyses.

\begin{tabular}{|c|c|c|c|c|c|c|c|}
\hline Element & $\begin{array}{c}\text { Alloy } \\
\text { wt \%) }\end{array}$ & $\begin{array}{c}140 \\
\text { hours, } \\
700^{\circ} \mathrm{C}\end{array}$ & $\begin{array}{c}200 \\
\text { hours, } \\
700^{\circ} \mathrm{C}\end{array}$ & $\begin{array}{c}200 \\
\text { hours, } \\
725^{\circ} \mathrm{C}\end{array}$ & $\begin{array}{c}200 \\
\text { hours, } \\
750^{\circ} \mathrm{C}\end{array}$ & $\begin{array}{c}200 \\
\text { hours, } \\
775^{\circ} \mathrm{C}\end{array}$ & $\begin{array}{c}200 \\
\text { hours, } \\
800^{\circ} \mathrm{C}\end{array}$ \\
\hline $\mathrm{O}$ & $\begin{array}{c}<220 \\
\mathrm{ppm}\end{array}$ & 15.8 & 20.9 & 24.1 & 27.9 & 31.8 & 31.1 \\
\hline $\mathrm{Cr}$ & 15 & 15.4 & 19.3 & 25.5 & 29.6 & 40.1 & 44.3 \\
\hline $\mathrm{Ni}$ & $\mathrm{Bal}$. & 39.7 & 32.6 & 24.4 & 18.8 & 8.6 & 5.0 \\
\hline $\mathrm{Ti}$ & 3.6 & 3.4 & 4.8 & 6.8 & 7.8 & 11.9 & 15.2 \\
\hline $\mathrm{Co}$ & 18.5 & 15.7 & 13.2 & 10.5 & 8.4 & 4.1 & 2.7 \\
\hline $\mathrm{Mo}$ & 5.0 & 4.7 & 3.6 & 2.8 & 2.1 & 0.9 & 0.3 \\
\hline $\mathrm{Al}$ & 3.0 & 3.3 & 2.6 & 2.3 & 2.4 & 1.1 & 0.6 \\
\hline $\mathrm{Ta}$ & 2.0 & 2.0 & 3.1 & 2.8 & 3.1 & 1.4 & 0.6 \\
\hline $\mathrm{Hf}$ & 0.5 & - & - & - & - & - & - \\
\hline $\mathrm{Zr}$ & 0.06 & - & - & - & - & - & - \\
\hline $\mathrm{C}$ & 0.027 & - & - & - & - & - & - \\
\hline $\mathrm{B}$ & 0.015 & - & - & - & - & - & - \\
\hline
\end{tabular}

Chen et al [7] studied the oxidation behaviour of nickel disc alloys Waspaloy, Astroloy and Udimet 720 after isothermal exposures at temperatures between 750 and $1000^{\circ} \mathrm{C}$. It was reported that XRD detected $\mathrm{Cr}_{2} \mathrm{O}_{3}, \mathrm{TiO}_{2}$ (rutile) and $\mathrm{NiCr}_{2} \mathrm{O}_{4}$ (spinel) oxides in these alloys following exposure at $750^{\circ} \mathrm{C}$ for 1000 hours. In addition to these oxides, $\mathrm{NiO}$ was also found in Astroloy after a 20 hour exposure at $750^{\circ} \mathrm{C}$.

Examination of Oxidation Damage Using Focused Ion Beam Microscopy

It had originally been planned to measure oxide thicknesses on polished cross-sections using backscattered imaging within a scanning electron microscope (SEM). However, the thin oxides found in this study made this preparation/examination route difficult. Therefore an alternative examination method was sought.

Focused Ion Beam (FIB) systems have been developed to prepare samples for use in transmission electron microscopy (TEM) by sputtering away trenches, using Ga ions, either side of a targeted area. However, FIB systems can also be used to cut a single trench and allow imaging of the structures revealed. A series of trials were carried out to investigate alternative sputtering and imaging methods using a FEI FIB 200 system. It was found that it was necessary to protect the surface of the oxide in the area to be examined during the sputtering process to avoid both contamination and stray sputter damage. This protection was provided using a layer of Pt, which was deposited in situ, by injecting an organo-Pt gas across the target area whilst illuminating it with the $\mathrm{Ga}$ ion beam. The $\mathrm{Ga}$ beam power was then increased to cut the trench, initially in coarse steps (at a 
current of 6600 and/or $11500 \mathrm{pA}$ ), then in finer steps to produce one flat side to the trench. The final stages of very fine ion milling were conducted using a current of 350 and/or $1000 \mathrm{pA}$, depending on the size of area being milled. An image was then produced via detected back scattered electrons that resulted from bombardment of the sample using the low power Ga ion beam, which scans the area of interest.

Focused ion beam examinations have revealed the appearance of the oxide scale and the formation of a complex near-surface damage microstructure. The FIB image in Figure 7 illustrates the features that have been observed, in this case, for an oxidised RR1000 surface, exposed to $700^{\circ} \mathrm{C}$ for 200 hours. The image shows a thin porous oxide scale immediately beneath the protective Pt strip. Below the oxide scale, there appear to be voids along grain boundaries between very small, sub $1 \mu \mathrm{m}$ grains. Since the average grain size in this form of heat treated RR1000 is typically between $4-8 \mu \mathrm{m}$, these near-surface grains appear to have been recrystallised either by the preparation of the samples or by oxidation. Further below the surface, larger voids exist. The FIB image also shows other aspects of microstructure including intragranular deformation twins and $\gamma^{\prime}$ particles.

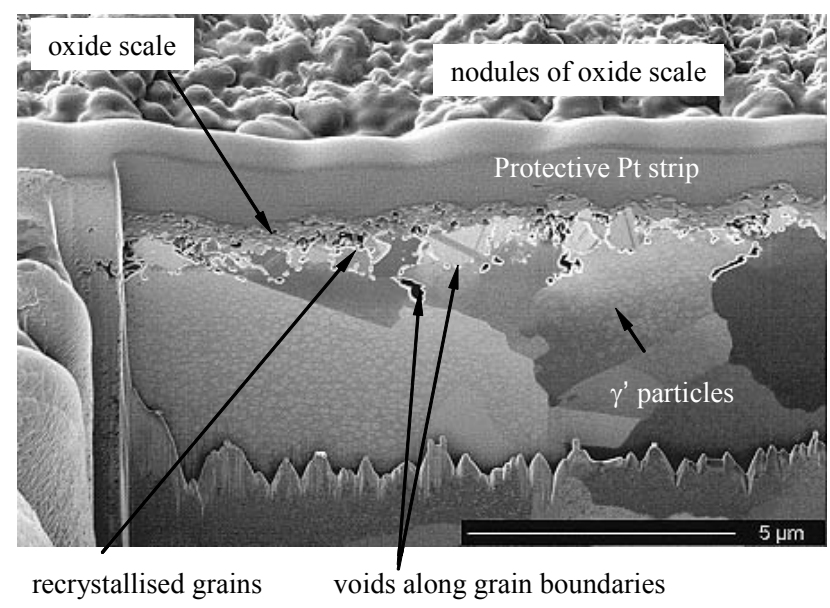

Figure 7. Focused ion beam image of an oxidised RR1000 surface, exposed to $700^{\circ} \mathrm{C}$ for 200 hours.

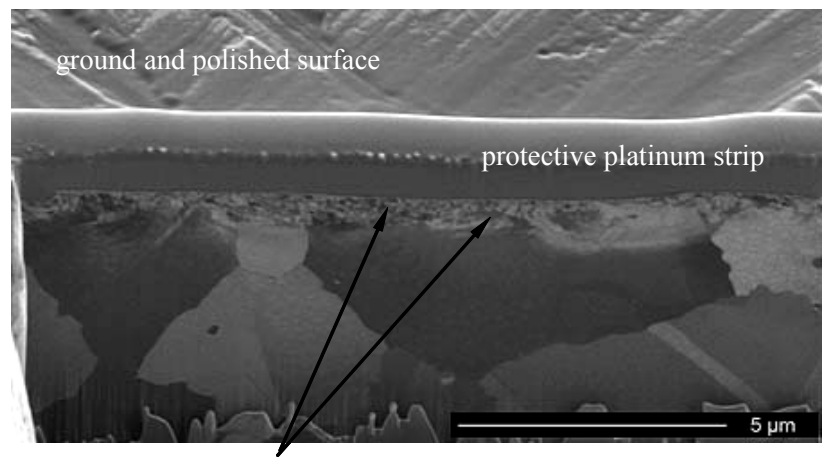

anomalies from surface preparation

Figure 8. Focused ion beam image of a ground and polished RR1000 sample prior to exposure.

Given the existence of recrystallised grains, a ground and polished RR1000 sample was examined prior to exposure. Whilst the image in Figure 8 does indicate very small anomalies from surface preparation, the sub $1 \mu \mathrm{m}$ grains illustrated in Figure 7 do not appear to be present. It can therefore be assumed that these are produced during oxidation testing.

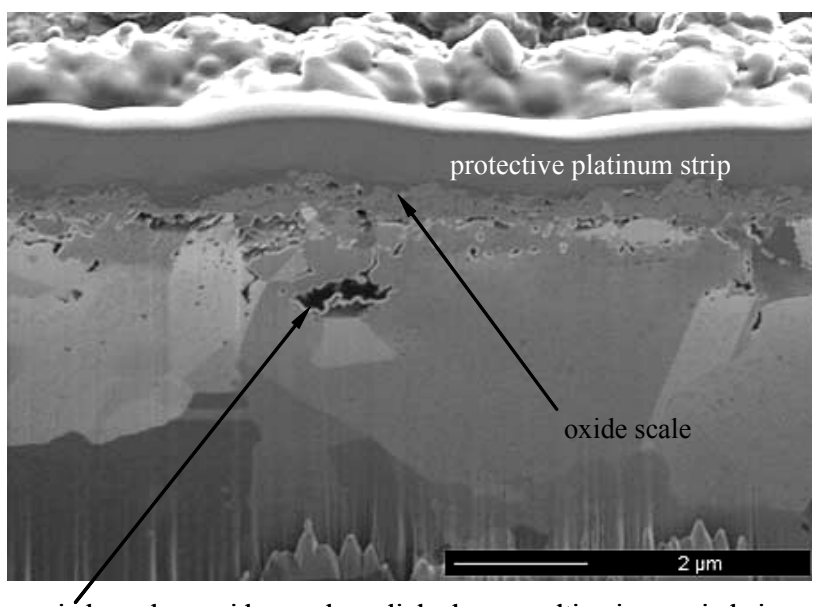

grain boundary voids may have linked up, resulting in a grain being removed

Figure 9. Focused ion beam image of an oxidised RR1000 surface, exposed to $750^{\circ} \mathrm{C}$ for 200 hours.

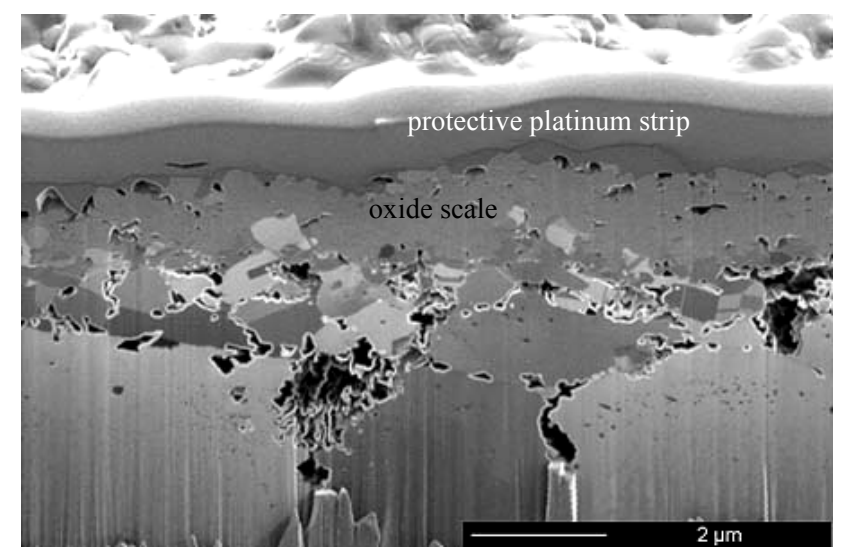

Figure 10. Focused ion beam image of an oxidised RR1000 surface, exposed to $800^{\circ} \mathrm{C}$ for 200 hours.

The observation of the grain boundary voids is consistent with the mechanism of $\mathrm{Cr}$ and $\mathrm{Ti}$ diffusion to the surface to form chromia, rutile and other spinel oxides (such as $\mathrm{NiCr}_{2} \mathrm{O}_{4}$ ). The vacancies left by $\mathrm{Cr}$ and $\mathrm{Ti}$ diffusion may coalesce to reduce surface energy and produce the observed voids. The development of oxidation damage with temperature is shown in Figures 9 and 10. There is an increased propensity for recrystallised grains and voids at higher temperatures of 750 and $800^{\circ} \mathrm{C}$, as well as an increase in thickness of oxide scale. It is considered that pores may be $3 \mathrm{D}$ voids around grain boundaries that link up, so that grains fall out (Figure 9).

Some information regarding the composition of the oxide scale may be deduced from the FIB images as a result of atomic number contrast. The lighter regions of the oxide scale in Figure 10 indicate heavier elemental oxides than chromia, such as Ni oxides. 
Gabb et al [2] observed oxide scale and damage in coarse grain Udimet 720 and ME3, from metallographic sections, which were taken from the parallel gauge sections of fatigue test pieces. SEM secondary electron images of test pieces that were either preexposed or tested in air at 650 and $704^{\circ} \mathrm{C}$ showed a continuous oxide scale, which was reported to be made up of $\mathrm{Ni}$ and $\mathrm{Co}$ oxides. Below this scale, "branched fingers" rich in Al oxide were observed. In regions adjacent to these fingers, it was noted that $\gamma$ ' was absent. It is suggested that these fingers are voids at recrystallised grain boundaries. Since the width of the fingers appeared to be less than $1 \mu \mathrm{m}$, they are thus too small to be isolated in the "interaction volume" for EDX. It can therefore be assumed that the area around the grain boundary voids may be rich in $\mathrm{Al}$ and $\mathrm{O}_{2}$.

Focused ion beam examinations have been used to confirm the low rates of oxidation and the calculated thickness of oxide scale. As oxide scale develops as nodules, the thickness of oxide scale and depth of oxidation damage have a range of values. Figure 11 compares the upper measured values of oxide scale and nearsurface oxidation damage from FIB examinations with calculated values of chromia scale. It indicates that the calculated values for the thickness of oxide scale show good agreement to the measured values, despite the results of energy dispersive X-ray analyses in Table II, which have identified that scale contains $\mathrm{Ni}$ and $\mathrm{Co}$ oxides, particularly at $700^{\circ} \mathrm{C}$, as well as $\mathrm{Cr}$ and $\mathrm{Ti}$ oxides. Figure 11 also suggests that calculated values of oxide scale from TGA or cyclic oxidation testing underestimate the damage from oxidation, and that FIB examination of exposed surfaces may offer the best approach to characterise thin oxide scale and oxidation damage in nickel disc alloys.

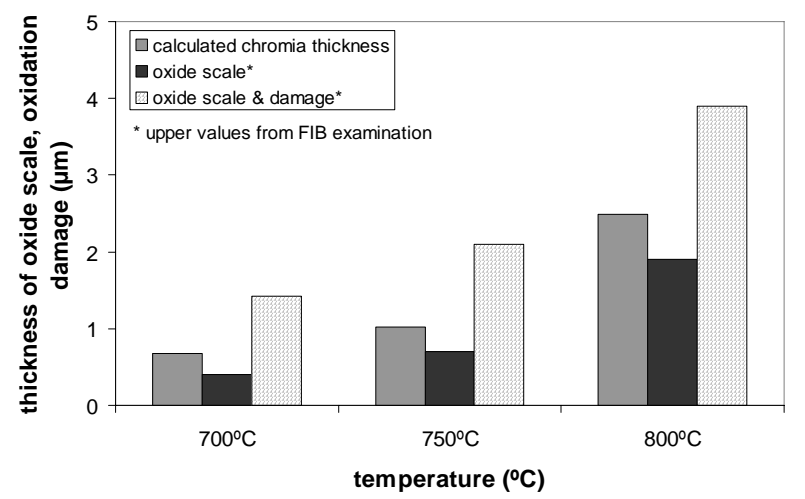

Figure 11 Oxide scale and oxidation damage in RR1000 after 200 hours exposure in air. Measured values from FIB observations are compared with calculated values for the thickness of chromia scale.

Gabb et al [2] measured the thickness of oxide scale and depth of oxidation damage from SEM images taken of exposed coarse grain Udimet 720 . The depth of oxidation damage being measured from the deepest tips of "Al oxide fingers". Some of the fatigue test pieces were pre-exposed at $704^{\circ} \mathrm{C}$ for 100 and 1029 hours and then tested for up to $\sim 200,000$ cycles or approximately 29 hours at temperature. Data from these test pieces (Table III) can therefore be compared with data (Figure 11) from the current study for exposed samples after 200 hours at $700^{\circ} \mathrm{C}$. This comparison indicates that the rate of oxidation damage in these alloys is similar, with Udimet 720 showing slightly higher rates of oxidation damage. The increased oxidation damage, however, may result from strain excursions during a portion of the total exposure time, although the level of plasticity incurred in the fatigue testing was small, since the total strain range was $0.7 \%$.

Table III. Thickness of oxide scale and depth of oxidation damage data for coarse grain Udimet 720 after exposures at $704^{\circ} \mathrm{C}$ (from Gabb et al [2]). * indicates data calculated from linear interpolations between (thickness of oxide scale) $)^{2}$ and (tips of "Al oxide fingers") $)^{2}$ versus time data.

\begin{tabular}{|c|c|c|}
\hline $\begin{array}{c}\text { Pre-exposure } \\
\text { time (hours) }\end{array}$ & $\begin{array}{c}\text { Thickness of } \\
\text { oxide scale }(\mu \mathrm{m})\end{array}$ & $\begin{array}{c}\text { Depth of Al } \\
\text { oxide tips }(\mu \mathrm{m})\end{array}$ \\
\hline 100 & $0.5-0.8$ & $1.1-1.8$ \\
\hline 1029 & $1.0-2.2$ & $2.5-8.5$ \\
\hline $200^{*}$ & $0.6-1.1^{*}$ & $1.3-3.3^{*}$ \\
\hline
\end{tabular}

\section{Laboratory Experiments to Simulate Hot Corrosion}

A series of hot corrosion tests have been undertaken on RR1000 samples using the 'deposit recoat' method $[9,10]$. This laboratory test has proved to be an effective way of simulating "in service" deposit conditions, and now forms the basis for EU recommended guidelines for hot salt corrosion testing [11]. It involves exposing samples, coated with controlled quantities of $\mathrm{Na}_{2} \mathrm{SO}_{4} / \mathrm{NaCl}$ 'deposits' to a controlled atmosphere in a furnace. To achieve these simulated 'deposition' conditions, samples are removed from the furnace and sprayed with 'deposit' to achieve the desired flux. The hot corrosion tests were targeted at evaluating the performance of RR 1000 when exposed at $700^{\circ} \mathrm{C}$ for 200,300 or 500 hour periods in a gas stream of air- $300 \mathrm{vpm} \mathrm{SO}_{2}$ and coated with deposits of $\mathrm{Na}_{2} \mathrm{SO}_{4}-2$ or $5 \% \mathrm{NaCl}$ at deposition fluxes, i.e. rates of deposition, of 2 or $10 \mu \mathrm{g} / \mathrm{cm}^{2} / \mathrm{h}$. Experience with blade/vane alloys, comparing test data with engine run parts, indicates that the test conditions applied in these laboratory simulations give acceleration of 5-10 times reality within the 500 hour test period.

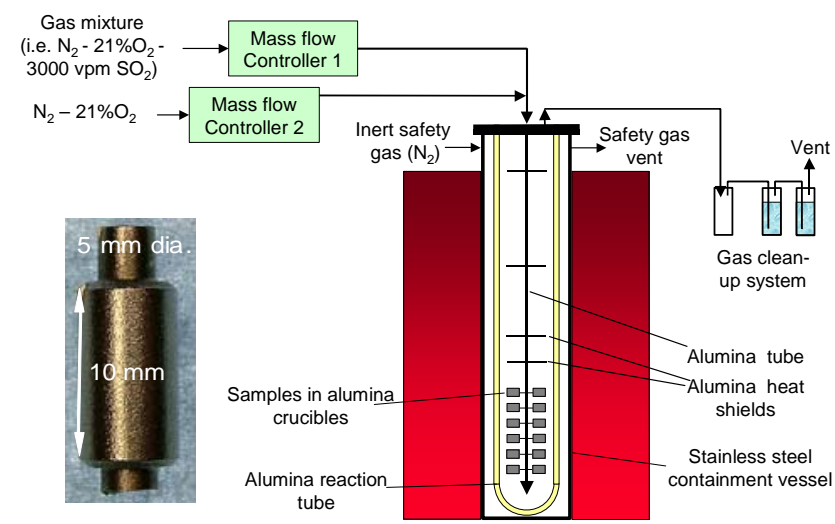

Figure 12. Schematic diagram of vertical furnace used for simulating hot corrosion.

Samples are cylindrical and are centreless ground to achieve a surface roughness of $0.4 \mu \mathrm{m}$, a length of $10 \mathrm{~mm}$ and a diameter of $5 \mathrm{~mm}+/-0.05 \mathrm{~mm}$. In these preliminary experiments, samples were exposed in the as-ground condition and not shot peened, as 
indicated in Figure 12. A small notch was introduced to one end of each sample to give an origin marking for dimensional metrology. Prior to exposure, samples were cleaned for 15 minutes in a degreaser (Volasil) in an ultra-sonic bath followed by a further cleaning 15 minutes in isopropyl alcohol. Samples were sprayed with a mist of solution through an artist's air-brush onto a sample pre-heated to approximately $120^{\circ} \mathrm{C}$. Water evaporation from the hot surface of the sample leaves an even layer of the desired salt on the sample surface.

The equipment used for these tests was a vertical controlled atmosphere furnace (Figure 12), with gases supplied from premixed gas bottles via mass flow controllers and with the gases exiting to a vent via a scrubbing system (to remove $\mathrm{SO}_{\mathrm{X}}$ ) and a water trap. The sintered alumina reaction tube used in this furnace had a length of $\sim 800 \mathrm{~mm}$, internal diameter of $\sim 70 \mathrm{~mm}$ and wall thickness of $\sim 5 \mathrm{~mm}$. The outer metal tube was for safety containment of the reaction gases should the reaction tube fail. The samples were exposed in this furnace in individual alumina crucibles (22 per furnace). The crucibles were held in an alumina frame. Prior to starting each test, the furnace was calibrated such that samples would be exposed in the hot-zone within a range of $+/-5^{\circ} \mathrm{C}$ of the target test temperature of $700^{\circ} \mathrm{C}$.

The gas atmosphere was supplied to the top of the furnace and allowed to flow downwards through the central alumina support tube before flowing backup the furnace around the samples and finally exiting through the top of the furnace. The gas composition used to create a hot corrosion environment was 300 vpm $\mathrm{SO}_{2}$ in air. The gas flow rate was $50 \mathrm{ml} \mathrm{min}^{-1}$ and was regulated by a pre-calibrated mass flow controller with an accuracy of $+/-1 \%$.

The samples were loaded into a furnace at room temperature $\left(25^{\circ} \mathrm{C}\right)$. This was sealed and purged with $\mathrm{N}_{2}$ before heating. The reaction gas was introduced during the heating cycle at around $400^{\circ} \mathrm{C}$. After the required exposure time was completed, the furnace was extensively purged with dry $\mathrm{N}_{2}$ and cooled before removing the samples at room temperature. After every exposure cycle all samples were stored in desiccators before being processed. Two samples were exposed to each test condition (for each salt composition and rate of salt deposition examined) to assess sample-to-sample variation in corrosion.

The RR1000 samples exposed in the hot corrosion tests showed morphologies indicative of type II hot corrosion damage, i.e. shallow/broad pitting damage, with the inner corrosion product/deposit layer rich in $\mathrm{S}$ and $\mathrm{Cr}$, and the outer layer with higher levels of $\mathrm{Ni}$ and $\mathrm{Co}$ (Figure 13). No evidence of internal oxidation or ingress of corrosion was observed.

\section{Characterising Hot Corrosion}

During their exposure, the progression of the hot corrosion damage to the samples is monitored using mass change methods. However, such methods are well known for their limitations when studying pitting type damage mechanisms. To quantify hot corrosion damage, samples were subjected to dimensional metrology before and after exposure. The diameters of the cylindrical samples are measured at a series of circumferential positions, at the mid-height location, prior to their exposure. After exposure, the dimensions of the samples are measured at this mid-height location using an image analysis system linked to an optical microscope (Figure 14). These methods allow metal losses, i.e. the depth of corrosion pits, to be calculated at over 24 positions around each sample.

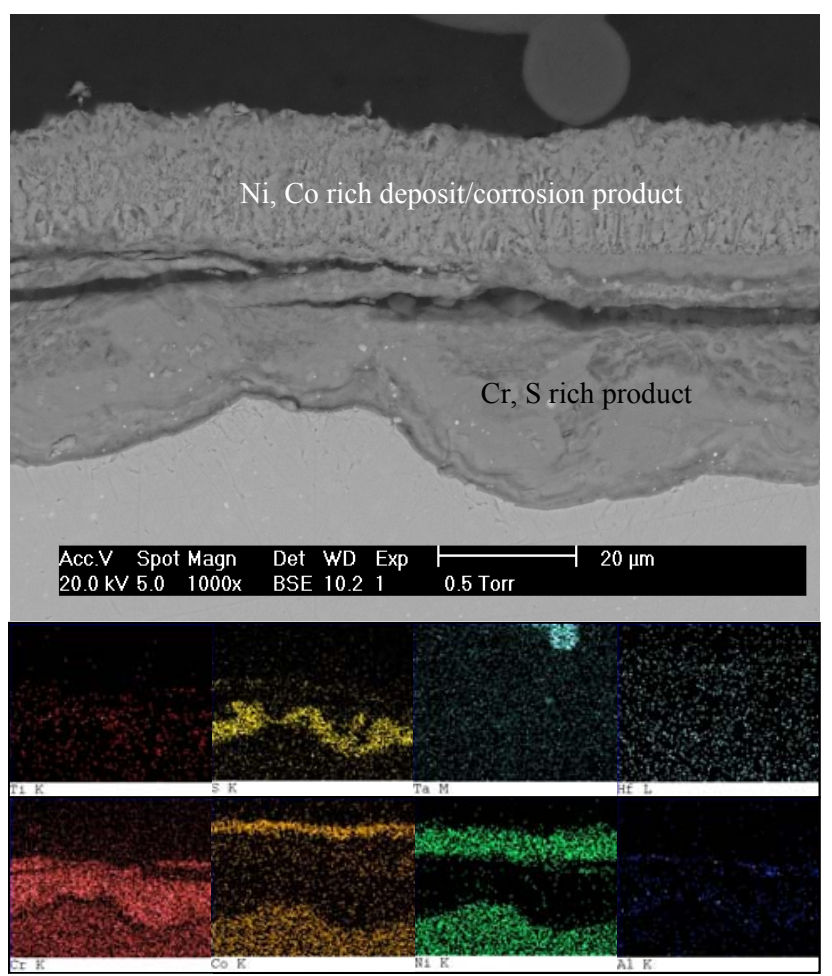

Figure 13 Backscattered electron image of corrosion pit in RR1000 after 300 hours exposure in an air - $300 \mathrm{vpm} \mathrm{SO}_{2}$ environment at $700^{\circ} \mathrm{C}$ with a salt deposit of $98 \% \mathrm{Na}_{2} \mathrm{SO}_{4}, 2 \%$ $\mathrm{NaCl}$ and a salt deposition rate of $2 \mu \mathrm{g} / \mathrm{cm}^{2} / \mathrm{h}$. Also shown is element mapping, from energy dispersive $\mathrm{x}$-ray analysis.

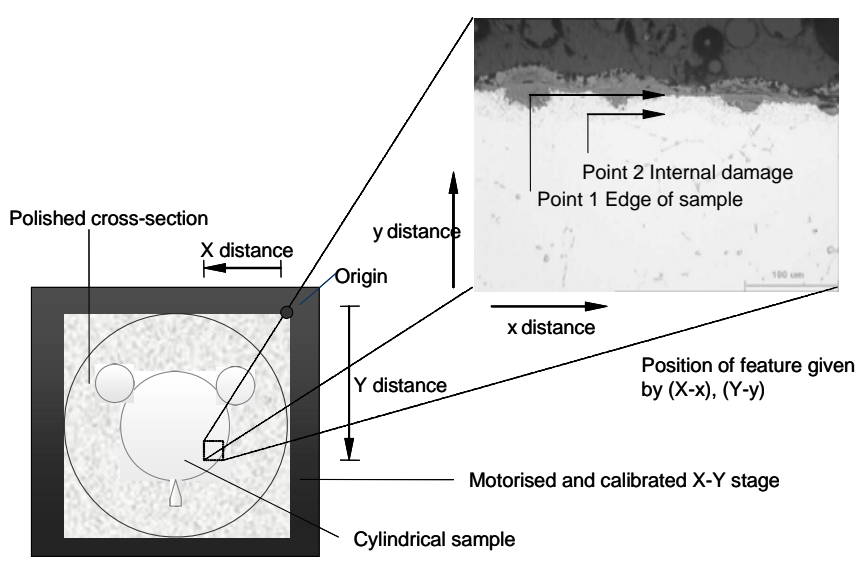

Figure 14. Quantifying hot corrosion using dimensional metrology.

The distributions of metal loss data that are generated can be analysed to give median damage, exceedance cumulative probabilities or extreme value statistics [10]. The cumulative probability, $\mathrm{P}\left(\mathrm{x}_{(i)}\right)$, of the $i$ th largest maximum pit size is calculated from: 


$$
P\left(x_{(i)}\right)=\frac{i}{(N+1)}
$$

where $\mathrm{N}$ is the total number of pit sizes.

\section{$\underline{\text { Effect of Salt Composition and Deposition Rate on Hot Corrosion }}$}

Figure 15 shows the variation in metal loss data with salt composition and rate of deposition for RR1000. Within the limited sample of test data, RR1000 shows little sample-to-sample variation. Given the steep curves, the data also indicate that there is a small variation in pit size within each sample.

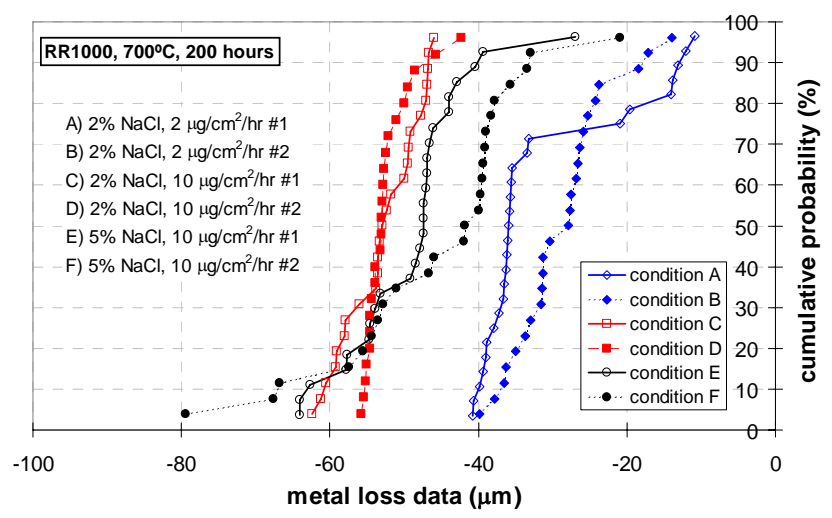

Figure 15. Variation in metal loss (pit depth) for RR1000 after exposures of 200 hours in an air - $300 \mathrm{vpm} \mathrm{SO}_{2}$ environment at $700^{\circ} \mathrm{C}$. The data shows the effect of salt composition $(\% \mathrm{NaCl}$ shown, remainder is $\mathrm{Na}_{2} \mathrm{SO}_{4}$ ) and deposition rate on hot corrosion.

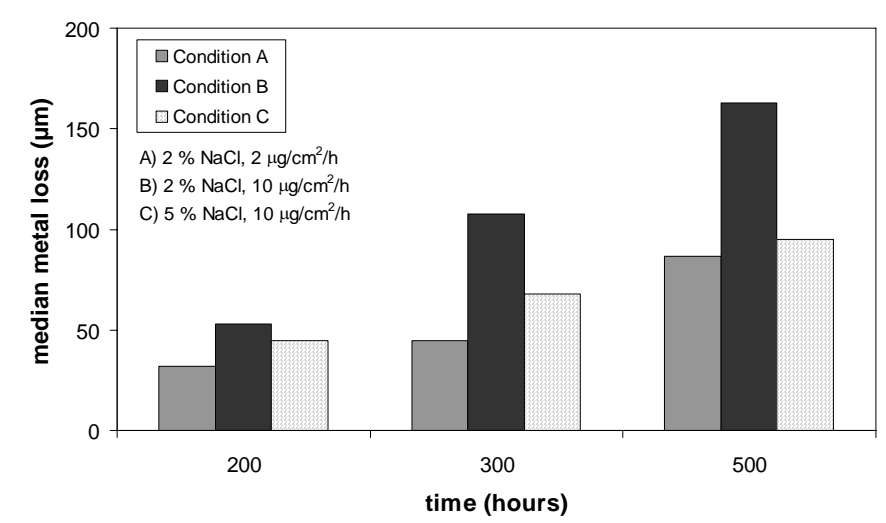

Figure 16. Median metal loss (pit depth) for RR1000 after exposures of 200, 300 and 500 hours in an air $-300 \mathrm{vpm} \mathrm{SO}_{2}$ environment at $700^{\circ} \mathrm{C}$. The data shows the effect of salt composition (\% $\% \mathrm{NaCl}$ shown, remainder is $\mathrm{Na}_{2} \mathrm{SO}_{4}$ ) and deposition rate on hot corrosion.

It is evident from Figure 15 and 16 that the level of hot corrosion increases with increasing deposition flux (rate of deposition) but decreases with increasing $\mathrm{Cl}$ content in the deposited salt.

Moreover, it is the contribution of $\mathrm{Na}_{2} \mathrm{SO}_{4}$ that determines the degree of type II sulphidation in RR1000. This behaviour has also been found in data from nickel disc alloys Waspaloy and 720Li [12]. As expected, the median metal loss data in Figure 16 shows that pit depth increases with exposure time. On the basis of the observed correlation between corrosion and deposition flux, it is considered that periodic cleaning of material to remove salt and $\mathrm{Na}_{2} \mathrm{SO}_{4}$ deposits will reduce the rate of corrosion.

\section{Effect of Potential Contaminants on Hot Corrosion}

Whilst initial work has focused on the corrosion of clean RR1000 alloy, in practice components can be subjected to contaminants during assembly, and during shop visits. Consequently, a small number of samples were first coated with a lubricant or an alkaline solution to evaluate the effect of these on hot corrosion damage. For these experiments, samples were tested in the shot peened condition. Details of these chemicals are given below:

- Lubricant: Aerospec 350 grease. Solvent refined base oil, containing $15-30 \% \mathrm{Li}$ complex soap thickner and graphite lubricating solids. Wavelength dispersive X-ray fluorescence was used to identify minor element constituents. It was found that the grease also contained $0.93 \% \mathrm{Ca}, 0.33 \mathrm{wt}$. $\% \mathrm{~S}, 0.12$ wt. \% P and 0.12 wt. \% Zn.

- Alkaline cleaning solution: Ardrox 185L. Contains 10-25\% sodium hydroxide $(\mathrm{NaOH})$.

The $\mathrm{NaOH}$ cleaning agent and the grease were applied onto samples only at the beginning of the test, i.e. a single application. To apply the $\mathrm{NaOH}$ cleaning agent, the sample was submersed into a crucible with the cleaning agent and placed in an oven at $40^{\circ} \mathrm{C}$ for 24 hours. The lubricant was applied by rolling the sample in a Petri dish with a small quantity of Aerospec 350 grease. It is recognised that these application techniques may result in an excessive dose of contaminant. However, it was considered that this approach would identify whether the corrosion resistance of RR1000, as an example of a nickel disc alloy, is sensitive to these contaminants.

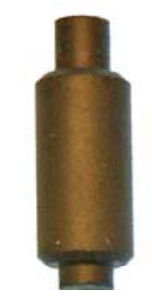

contaminant free RR10000

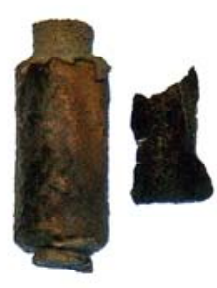

grease

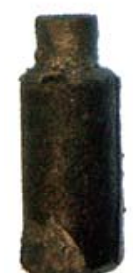

$\mathrm{NaOH}$ cleaning solution
Figure 17. Appearance of samples exposed after 200 hours in air 300 vpm $\mathrm{SO}_{2}$ at $700^{\circ} \mathrm{C}$ (screening test).

The images in Figure 17 show the appearance of the samples after 200 hours of exposure, in a screening test, which was undertaken in a horizontal furnace, similar to the one shown schematically in Figure 2. In this test, the samples were not subject to salt deposit re-coats but were just exposed at $700^{\circ} \mathrm{C}$ in air with $300 \mathrm{vpm} \mathrm{SO}_{2}$. Whilst the contaminant free RR1000 exhibits few indications of hot corrosion, the contaminated samples show significant corrosion damage and spallation.

In further testing, undertaken in the vertical furnace in Figure 12, samples were given a single application of either lubricant or $\mathrm{NaOH}$ cleaning agent at the start of the test then sprayed with salt as described in the earlier section. Salt deposit $\left(98 \% \mathrm{Na}_{2} \mathrm{SO}_{4}, 2\right.$ $\% \mathrm{NaCl}$ ) was applied every 50 hours at a rate of deposition of 10 
$\mu \mathrm{g} / \mathrm{cm}^{2} / \mathrm{h}$. The gas used in the controlled atmosphere furnace was the same as in previous tests, i.e. air $-300 \mathrm{vpm} \mathrm{SO}_{2}$. After exposure, samples were mounted with low shrinkage resin mixed with glass spheres, of $40-70 \mu \mathrm{m}$ in diameter, to further reduce shrinkage. The filled mounts were vacuum heat treated to minimise porosity. Once the resin had set, the samples were cut perpendicularly to their long cylindrical axes using a CBN slitting wheel with oil as a lubricant. Standard $\mathrm{SiC}$ and diamond pastes were used in the preparation of polished cross sections. Mineral oil was used as a lubricant to avoid the dissolution of the salt.
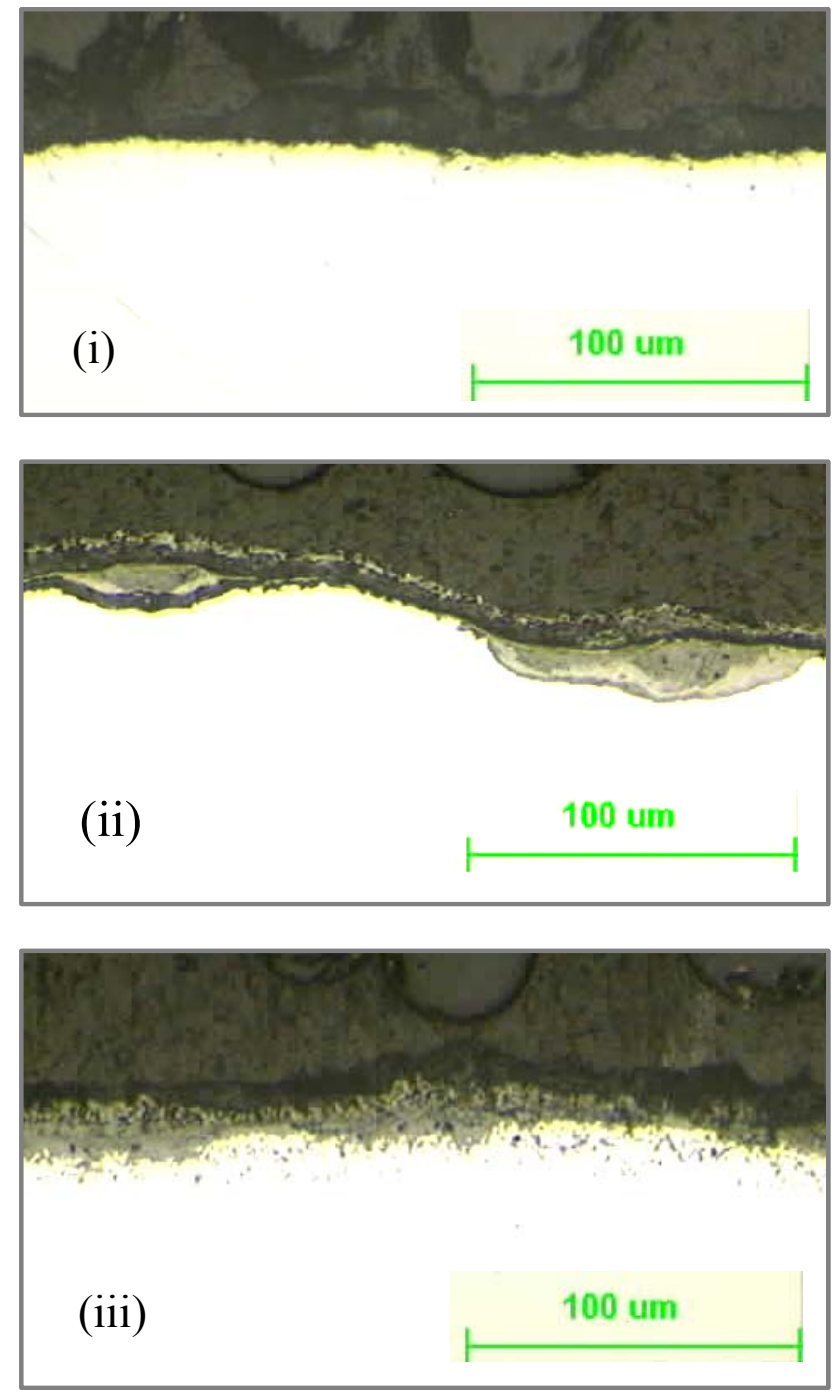

Figure 18. Optical microscope images showing sections from samples exposed to 200 hours in an air - $300 \mathrm{vpm} \mathrm{SO}_{2}$ environment at $700^{\circ} \mathrm{C}$, with a salt of $98 \% \mathrm{Na}_{2} \mathrm{SO}_{4}, 2 \% \mathrm{NaCl}$ deposited at a rate of $10 \mu \mathrm{g} / \mathrm{cm}^{2} / \mathrm{hr}$ : (i) contaminant free RR1000, (ii) RR1000 with grease, (iii) RR1000 with $\mathrm{NaOH}$ based cleaning solution.

Figure 18 shows images of polished cross-sections after 200 hours of exposure. It is evident from the significant pitting in image (ii), compared to the corrosion damage in (i) from contaminant free RR1000, that the presence of the lubricant has dramatically accelerated the corrosion of RR1000. The corrosion damage, however, remains typical of type II sulphidation, i.e. shallow broad front pits with no internal damage. This is not the case for the sample exposed to the $\mathrm{NaOH}$ cleaning agent (Figure 18 (iii)), which shows evidence of internal damage beneath the surface corrosion.

The observed increase in corrosion damage shown in Figures 17 and 18 as a result of the cleaning solution and lubricant is quantified in Figure 19 with metal loss data from dimensional metrology. These data indicate that the contaminants, rich in $\mathrm{Li}$ and $\mathrm{Na}$, have increased the median pit depth in RR1000 by a factor of approximately 2 and 3 respectively.

The internal damage observed in Figure 18(iii) is considered to have resulted from the increased concentration of $\mathrm{Na}$, provided by the contaminant. Sodium is established as a strong $\mathrm{S}$ getter, reacting with $\mathrm{SO}_{3}$ to form $\mathrm{Na}_{2} \mathrm{SO}_{4}$, one of the compounds known to promote type II sulphidation damage. It is likely that the high concentration of $\mathrm{Na}_{2} \mathrm{SO}_{4}$ will quickly dissolve the surface oxide, leaving $\mathrm{Na}_{2} \mathrm{SO}_{4}$ eutectic solid-liquid mixtures. Once the eutectics form and the outer protective oxide have been dissolved, substrate attack is initiated, initially forming metal sulphides of those elements, such as $\mathrm{Ni}$, that are most readily sulphidised. The next easiest sulphidising element is sulphidised once $\mathrm{Ni}$ has been consumed from that location. In this manner, a non protective outer scale develops, with the sulphides forming sulphates, which are then oxidised as the partial pressure of $\mathrm{O}_{2}$ increases towards the outer scale surface. Sulphur is able to penetrate deeper into the substrate along grain boundaries, reacting with $\mathrm{Cr}$ forming $\mathrm{CrS}$, which depletes the surrounding grain boundary in Cr. Attack therefore occurs down the less corrosion resistant grain boundaries, leaving voids at the front of the deepest areas of grain boundary attack.

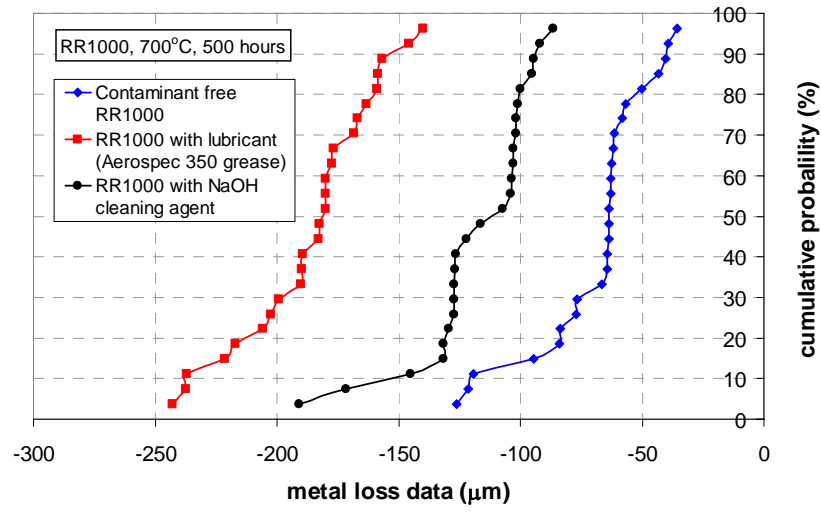

Figure 19. Variation in metal loss (pit depth) for RR1000. Data are from 500 hour exposure in an air $-300 \mathrm{vpm} \mathrm{SO}_{2}$ environment and a salt of $98 \% \mathrm{Na}_{2} \mathrm{SO}_{4}, 2 \% \mathrm{NaCl}$ deposited at a rate of 10 $\mu \mathrm{g} / \mathrm{cm}^{2} / \mathrm{hr}$. The graph shows the effect of a grease and a cleaning solution $(\mathrm{NaOH})$ on hot corrosion.

\section{Conclusions}

The oxidation kinetics of RR1000 have been characterised from mass change data that have been generated from: 
(i) a series of isothermal exposures, up to 200 hours, that were undertaken in a thermogravimetric analysis (TGA) system at temperatures between 700 and $800^{\circ} \mathrm{C}$,

(ii) cyclic oxidation tests, which were conducted at 700 and $750^{\circ} \mathrm{C}$, with exposures up to 1000 hours, with intervals after every 100 hours.

Thin oxides were generated in the majority of these exposures. Initially, surface oxides were characterised using X-ray diffraction and energy dispersive X-ray analysis. Further consideration of alternative analytical techniques for thin oxides has lead to the use of focused ion beam (FIB) microscopy to characterise the thickness of oxide scale and the depth of near-surface damage, which has resulted from oxidation.

The results of these tests indicate that slowly growing $\mathrm{Cr}$ and $\mathrm{Ti}$ rich oxide scales form on the surface of RR1000 during oxidation in air at temperatures between 700 and $800^{\circ} \mathrm{C}$. Such oxide scales has been found to grow via a parabolic dependence with time. Consequently parabolic oxidation rate constants have been correlated with temperature using an Arrhenius equation. Through the use of simplifying assumptions, mass change data have been converted to oxide thickness values.

Measurements of thin oxides from FIB microscopy have shown that the range of values for oxide scale thickness is consistent with average values that have been calculated from mass change data. However, it is considered that FIB examination of exposed surfaces offers the best approach in characterising the maximum depth of thin oxide scale and oxidation damage in nickel disc alloys.

Laboratory 'deposit' recoat experiments at $700^{\circ} \mathrm{C}$ have found that hot corrosion in nickel disc alloy RR1000 takes the form of broad, shallow pitting damage, which is typical of type II sulphidation. This damage produces an inner corrosion product/deposit layer, which is rich in $\mathrm{S}$ and $\mathrm{Cr}$ and an outer layer showing higher levels of $\mathrm{Ni}$ and $\mathrm{Co}$. No evidence of internal oxidation or ingress of corrosion in uncontaminated RR1000 was observed.

Levels of corrosion have been found to increase with increasing rate of salt deposition, but decreased with increasing $\mathrm{Cl}$ content in the salt deposit, which was varied between 95 and $98 \% \mathrm{Na}_{2} \mathrm{SO}_{4}$. As corrosion pit depth also increased with exposure time, it is considered that periodic cleaning of material to remove salt and sodium sulphate deposits will reduce the rate of corrosion.

Contaminants rich in $\mathrm{Li}$ and $\mathrm{Na}$ were shown to accelerate corrosion in RR 1000 at $700^{\circ} \mathrm{C}$.

\section{Acknowledgements}

Part of this research has been undertaken in the MACE (Materials for Arduous Cycle and Emissions) Project (TP/2/ET/6/I/10037), which forms part of the UK government Department of Trade and Industry Technology Programme. Rolls-Royce and Cranfield University would like to acknowledge the financial support provided by the Department of Trade and Industry. The authors would also like to thank Colin Small of Rolls-Royce for coordination of the MACE Project and Rolls-Royce for permission to publish this work.

\section{References}

1. S. Floreen and R. Raj, "Environmental Effects in Nickel-Base Alloys", Flow and Fracture at Elevated Temperatures, Ed. R. Raj, (American Society of Metals, 1984), 383-405.

2. T. P. Gabb, J. Teleman, P.T. Kantzos, J.W. Smith and P.F. Browning, "Effects of High Temperature Exposures on Fatigue Life of Disk Superalloys", Superalloys 2004, Ed. K.A. Green et al, (Warrendale, Pennsylvania, USA, The Minerals, Metals \& Materials Society, 2004), 269-274.

3. A. Pineau, "High Temperature Fatigue of Ni-Base Superalloys: Microstructural and Environmental Effects", Engineering Against Fatigue, Ed. J.H. Beynon et al, (Rotherdam, the Netherlands, A.A. Balkema, 1999), 557-565.

4. D.A. Woodford, "Gas Phase Embrittlement and the Time Dependent Cracking of Nickel Based Superalloys, Energy Materials: Materials Science and Engineering for Energy Materials, 1, (2006), 59-79.

5. M.C. Hardy, B. Zirbel, G. Shen and R. Shankar, "Developing Damage Tolerance and Creep Resistance in a High Strength Nickel Alloy for Disc Applications", Superalloys 2004, Ed. K.A. Green et al, (Warrendale, Pennsylvania, USA, The Minerals, Metals \& Materials Society, 2004), 83-90.

6. W.C. Hagel and A.U. Seybolt, "Cation Diffusion in $\mathrm{Cr}_{2} \mathrm{O}_{3}$ ", J. Electrochem. Soc., 108, (1961), 1146-1152.

7. J.H. Chen, P.M. Rogers and J.A. Little, "Oxidation Behaviour of Several Chromia-Forming Commercial Nickel-Base Superalloys", Oxidation of Metals, 47, (1997), 381-410.

8. J.M. Radowski, "The Oxidation of Metal Alloy Foils in the Presence of Water Vapor", Journal of Engineering for Gas Turbines and Power, 126, (2004), 867-873.

9. N. J. Simms, P. J. Smith, A. Encinas-Oropesa, S. Ryder, J.R Nicholls and J.E. Oakey, "The Development of Type II Hot Corrosion in Solid Fuel Fired Gas Turbines", Lifetime Modelling of High Temperature Corrosion Processes, (European Federation of Corrosion Publication No. 34, 2001), 246-260.

10. N. J. Simms, J.E. Oakey and J.R. Nicholls, "Development and Application of a Methodology for the Measurement of Corrosion and Erosion Damage in Laboratory, Burner Rig and Plant Environments", Materials at High Temperatures, 17 (2000), 355362.

11. 'Draft Code of Practice for Discontinuous Corrosion Testing in High Temperature Gaseous Atmospheres', EU Project SMT4CT95-2001, 'TESTCORR', ERA Technology, UK (2001),

12. M.C. Hardy, N.J. Simms and J.R. Nicholls, "Hot Corrosion Testing of Nickel Disc Alloys" (Rolls-Royce Technical Report DHC267700, Rolls-Royce, 2007). 